INTERNATIONAL JOURNAL OF MULTidisciplinARY RESEARCH AND ANALYSis

ISSN(print): 2643-9840, ISSN(online): 2643-9875

Volume 04 Issue 10 October 2021

DOI: 10.47191/ijmra/v4-i10-16, Impact Factor: 6.072

Page No.- $1441-1444$

\title{
The Image of the Modern Teacher and its Place in the Culture of Speech
}

\section{Tukhtasinov Abror Rustamovich}

Teacher of Namangan State University

ABSTRACT: There are aspects of dress that are related to a person's psyche, character, mood, upbringing, and taste. It is important to note that dress and customs did not arise spontaneously. There is no definitive conclusion as to when clothing appeared in human society. Man, who first learned to weave and sew fabrics from leather and wool, later gave comfort and beauty to clothes with the advent of cotton and silk fibers. Hence, the development of human thinking brought civilization to his dress as well.

KEYWORDS: popular culture, customs, traditions, spirituality, etiquette, morality, virtue.

\section{INTRODUCTION}

From time immemorial, mankind has worn clothes made of various fabrics and materials to protect their bodies from the effects of heat and cold, and the clothes reflect the values, traditions, attitudes of each nation, in short, its spirituality. Over time, outerwear has become a means of expressing a particular profession, and it has become possible to draw conclusions about the spirituality of each person based on their dress code. In recent years, the negative impact of "popular culture" has become a tradition in the clothing of young people. Protecting our youth from these influences, which are completely alien to our spirituality, is one of the most important state tasks facing educators. it is required to be able to evoke an aesthetic sense in the reader with a compact, mediocre dress. In this sense, this guideline is important in that the teacher provides students with examples of appropriate dress codes.

Humans have invented clothing since primitive times, at the same time as living and building dwellings. People used plant leaves, tree bark, and animal skins to protect their bodies from heat and cold. With the passage of time and the development of production, different types of clothes were made, made of different fabrics. The clothes reflect the historical traditions, social relations, enlightenment, religion and aesthetic views of each nation. Preacher Kashifi, who was the head of the teachers involved in the upbringing of children during the time of Hussein Boykaro, recommended 15 rules of dress code.[1]

He admits that "... Clothes should be bought for a fair amount of money, and the clothes should be worn for protection from heat and cold, not for clothing or decoration". According to the preacher Kashifi, "Wearing clothes is obligatory at the level of covering the body and the private parts"

\section{Today's demand for pedagogical staff dress.}

A spiritual person knows the purpose of life, strives to create beauty in his work, and has a high level of dress and manners. In the words of the First President of the Republic of Uzbekistan Islam Karimov, ". It is natural for every employee to have their own work clothes. Work clothes are sewn to suit the work process. The taste of the teacher's clothes, the aesthetics of the heart, the spirit of the times are an important requirement of the spirituality of our society. The teaching profession is a unique world, which is both difficult and generous. Teachers are people who are always surrounded by students and parents. In many cases, teachers lose their reputation because they are not interesting. Negative perceptions of the teacher's personality dampen interest in science. Thus, an interest in the teacher's personality is a means of developing an interest in the subject being studied. The teacher inspires the students to the meaning of life, and as a result, the teacher discovers "new horizons". Therefore, the image of the educator should be inspired. No matter how good a teacher is, he is always required to develop and improve his personal image and personal qualities. It should be noted that preschool educational institutions, general secondary schools, which are the center of education, contribute to the development of the younger generation in all respects mature, spiritually rich, harmoniously developed. serves as the main foundation. Therefore, the outerwear of every educator and teacher working in these institutions 


\section{The Image of the Modern Teacher and its Place in the Culture of Speech}

should be elegant and in line with the morale of the profession. This means that the teacher must be a role model to the students in every way. One example is the dress code. Because students are influenced by the teacher's dress during the lesson. The following responses were received from students during the interview:

"If a teacher is well-dressed, we will treat them with respect, even if we don't want to. The way a teacher dresses helps us to remember what we are talking about. So if he's well-dressed, we'll have more positive feedback and more confidence in him".

"Many teachers, according to their old habits, do not pay attention to the culture of dress, hairstyles and behavior. How can a student have an aesthetic taste if he or she has a tasteless teacher in the classroom from primary school?"

These thoughts are not in vain, but are vital plates. The educator must be an example to others in the school, in the community, with his knowledge, behavior, manners, high moral qualities, internal and external culture, exemplary lifestyle, dress code. It is recommended that educators adhere to the following dress code requirements:

Men: dark pants, light shirt, dark suit, neatly sewn, clean and ironed, tie. He should be well-groomed, have a clean beard, and wear shoes according to the season.

Women: a dark skirt and light blouse not higher than the knee, a dark suit should be neat, not too narrow or wide, clean and ironed. Hair should be curly, make-up should not exceed the norm, jewelry should not be worn, shoes should be worn in accordance with the season;

short skirts, tights of different colors and ornaments, stockings, revealing, colorful, light-colored dresses, spicy perfumes, and dyeing hair and nails in various forms are not recommended. It is advisable not to wear any (extra) jewelry on the hands, ears and neck.[2]

Experience of student dress code shows that in the educational institutions there are special clothes worn by students. At the heart of this is the idea of removing artificial barriers that distract students from learning. The same outfit instills in students a sense of equality and cooperation in many ways. And they only focus on reading and studying. The child, in turn, feels that he came to school to study and learn. In addition, the costumes of our nation create a creative atmosphere in educational institutions.

In view of the above, it is advisable to ensure that students come to secondary schools in appropriate school uniforms. In this regard, the ministry has developed requirements for the dress and appearance of students and received proposals from relevant organizations. Based on the suggestions received, each school was given the opportunity to choose a clothing design based on its regional characteristics. The choice of student clothing design should take into account the climatic conditions of the area, the characteristics of the age and physiological development of students, as well as their suitability for spiritual and moral values. Ensuring that students arrive in the school uniform in accordance with the school's charter, including that students' clothing is clean and tidy, that girls' hair is straight, and that they do not wear short skirts and dresses that are too revealing. as well as requirements for boys to have their hair straightened, not to come to school in shorts and a T-shirt, torn pants in their knees, and clothes depicting western militant movie heroes. These requirements are agreed upon with the parents of the students in the admission process.

For boys: dark pants, light shirt, dark suit should be neatly sewn, clean and ironed. It is recommended that boys wear a dark tie

For girls: a dark skirt and a light blouse not higher than the knee, a dark suit (sipo), elegant, not too narrow or wide, free of excess ornaments and colorless, must be clean and ironed. Hair should be styled in two or one part, free of make-up and jewelry should not exceed the norm (only compact braids are allowed)[3]

Requirements for student clothing:

- $\quad$ the fabric of the blouses should be made of non-reflective fabric;

- sewing clothes in a sipo and bejirim style;

- not too narrow or wide, not too long or too short;

- be in the middle (clean, ironed);

- $\quad$ made of dust-proof fabric.

- Student Appearance Requirements:

- $\quad$ girls keep their hair neat, their hair is curly, do not wear jewelry other than jewelry, and take care of themselves;

- $\quad$ boys' hair length should not exceed the norm $(2-3 \mathrm{~cm})$, be neat and walk in the - middle;

- $\quad$ students must keep their shoes clean and follow good hygiene practices.

According to the Charter of a general secondary school, the requirements for school teachers are as follows:

- the teacher has a good knowledge of the subject he teaches;

- to set an example to others in school, in the community with their 


\section{The Image of the Modern Teacher and its Place in the Culture of Speech}

- knowledge, behavior, high moral and spiritual qualities, internal and external culture, exemplary lifestyle, dress code;

- to refrain from engaging in socially unacceptable behavior, and to be aware of students' behavior;

- be active in improving the reputation of the school, the quality and effectiveness of education;

- high level of professionalism, ensuring that students master the curriculum at the level of state educational standards;

- to respect the personality of students, to educate them in the spirit of respect for existing laws, labor, parents, spiritual, historical, national and universal values;

- to educate the younger generation in the spirit of mutual understanding, peace, harmony and solidarity among peoples, nations and peoples, and to protect them from all forms of violence;

- they are required to constantly improve their professional skills[4]

There is such a legend about dress code. "A woman sentenced to death asked the guards for a rope and a needle as they led her to the execution. The guards asked why. Woman: I have a cut on my knee, I'll sew it on. Guard: What are you going to do now that you're dying? Woman: I am a woman! Save the shame. Even if I'm dying, I have a right to my honor, I have to be a woman in front of the people". It should be noted that technology is growing rapidly. It is natural that this development will also affect the dress code of educators and students. But the prestige of educators, whose spiritual image and inner world are exemplary, in the eyes of the student will always be an example of "It is better to see once than to hear a hundred times". Therefore, not only in the process of training, but also in the streets, weddings and neighborhood relations, the dress, manners, manners of education workers - has been and will continue to be an example to young people with his morals.

We live in a strange time: the world around us is changing so fast, so unrecognizably. Therefore, a teacher working with the younger generation should be prepared for:

Change. This is the most difficult, but necessary condition for existence as a full-fledged person.

Acknowledge your mistakes. Only someone who has done nothing will make a mistake. Of course, a teacher does not fall into that category.

Development. If the pace of the world hasn't changed in a few generations, it's now evolving so fast that, as the Black Queen in "Alice in Wonderland" puts it, we have to run".

The teacher must also understand what modern students live with.

Also, the teacher needs to keep in mind that modern students are different. They live on the Internet and have no adult culture. In order to benefit and enjoy the fruits of their labor, modern teachers and educators must have the following qualities.

\section{Respect for children}

It is often said that a teacher should love children. However, this idea is very abstract and can lead to different interpretations. After all, the concept of love is multifaceted. Everything is simple with the concept of respect. Respect for the reader means seeing the person in it, not the white paper.

\section{Tolerance}

People are all different. Sometimes it bothers us because we don't look like others: we wear different hats, we look different. If he behaves naturally and does not violate the rules of etiquette, should he pay attention to it? The same is true of the right to freedom of opinion. Unexpected and original suggestions should not be deleted immediately, as they are the only questions that cannot be answered correctly. They may be more consistent than standard answers. Children don't think like "stereotypes" like adults do, so they think freely. Recognize the student's right to be unique. Maybe you're perfecting the new Einstein.

\section{The teacher understands that he is serving}

For some reason, this issue irritates many teachers and parents. Maybe it's reputation. The word "teacher" sounds proud.

\section{Be willing to be respected for what is real}

You can't impress a modern child with loud words and commanding tone. Everything has to be Hamburg-like: a good teacher knows his subject well, can explain its benefits, and makes the material interesting. Intimidation is useless. Today's children are not afraid of what people used to fear.

\section{Feeling the limit}

This applies to both spiritual boundaries and personal knowledge. After all, in some ways children know more than teachers.

\section{Understand your role}

The teacher has to provide useful knowledge that cannot be found in the Google search engine (otherwise it is a waste of time).

\section{Self-criticism}

If a teacher analyzes his work and thinks about how to develop it, he will achieve a lot. Everyone can get lost. Big uncles and aunts are no exception. The sooner the kids realize this, the better. 


\section{The Image of the Modern Teacher and its Place in the Culture of Speech}

\section{Self-indulgence}

The ability to be serious and to be funny is an integral part of coping with stress. It is also an excellent quality for life in society. Self-humor can help ease a difficult situation, distract, and solve difficult problems.

Of course, it is not easy to have all the qualities. In many cases, the school does not have the opportunity to select teachers. But even so, it is necessary to strive for the ideal.

\section{REFERENCES}

1) Imamkhodjayev S. The art of oratory.-Tashkent: Teacher, 1992.- P.56

2) Kudratov T. Fundamentals of speech culture. Tashkent: Teacher, 1993.-P.32

3) Jumaniyozov R. "Speech skills". - T., "Adolat", 2005. -P.28

4) Kungurov R, Begmatov E., Tojiev Yo. "Fundamentals of speech culture and methodology." - T., "Teacher", 1992. -P.76.

5) Bekmirzaev N. Side notebook of the speaker. T., - “Fan”, 2007.- P.85. 